Indo Global Journal of Pharmaceutical Sciences, 2016; 6(1): 38-42

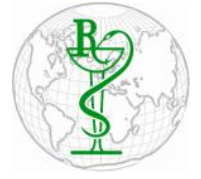

INDO GLOBAL JOURNAL OF

PHARMACEUTICAL SCIENCES

ISSN 2249- 1023

\title{
Review on Matrix Tablet
}

\author{
Tulsi Bisht ${ }^{1 *}$, Poonam Rishiwer ${ }^{2}$, Popin Kumar ${ }^{1}$ \\ ${ }^{1}$ Gyani Inder Singh Institute of Professional Studies, Dehra Dun, Uttrakhand, India \\ ${ }^{2}$ Shri Ventenkeshwara University, Gajrola, Uttar Pradesh, India
}

\begin{abstract}
Address for Correspondance

Tulsi Bisht, tulsibisht2009@g $\underline{\text { mail.com }}$

Keywords Matrix System; SR; Reservoir; Gelling Agent; NSAIDs.

ABSTRACT: Tablet is one of the most common and popular oral pharmaceutical oral dosage forms.Oral ingestion is most convenient and commonly employed route of drug delivery due to its ease of administration, least aseptic and flexibility in the design of dosage form. It is well known that modified release dosage forms may offer one or more advantage over immediate release formulation. One of such modified release dosage form is matrix delivery system, in which drug is uniformly dissolved or dispersed throughout the polymer matrix. In matrix diffusion- controlled system, the drug reservoir is prepared by homogenously dispersing drug particles in a hydrophilic or lipophilic polymer matrix. The resultant polymer is then molded into a medicated disc. Matrix system is one of the most innumerable methods used in the development of SR formulation. In simplest word, matrix is defined as a well composite of one or more drug with a gelling agent. Studies demonstrate that drug delivery from this system may reduce the side effect associated with the NSAIDs and provide extended therapeutic effect. The objective of this review is to discuss the release mechanism of drug from a matrix system and various polymers used in preparation of matrix tablet. $\odot 2015$ iGlobal Research and Publishing Foundation. All rights reserved.
\end{abstract}

\section{INTRODUCTION}

Matrix system are flavored because of their simplicity, patient compliance etc., than traditional drug delivery (TDS) which have many drawbacks like repeated administration, fluctuation in blood concentration level etc. Developing oral sustained release matrix tablets for highly water-soluble drugs with constant release rate has always been a challenge to the pharmaceutical technologist. Most of highly water-soluble drugs, if not formulated properly, may readily release the drug at a faster rate, and are likely to produce toxic concentration of the drug on oral administration. Hydrophilic polymers have become product of choice as an important ingredient for formulating sustained release formulations of highly water soluble drugs. Drug release through matrix system is determined by water penetration, polymer swelling, drug dissolution, drug diffusion and matrix erosion. Highly water soluble drugs like metoprolol tartarate, ditiazem, tramolol; ranitidine has been formulated as sustained release matrix tablets. Tablets offer the lowest cost approach to sustained and controlled release dosage forms. Matrix tablets serves as an important tool for oral extended- release dosage forms. Hence, problems like patient compliance, drug targeting, local side effects, frequent administration and fluctuations in blood concentration levels, associated with their counterparts, the conventional dosage forms were solved. Oral extended release drug delivery system becomes a very promising approach for those drugs that are given orally but having the shorter halflife and high dosing frequency. Extended- release drugdelivery system reduces the dosing frequency of certain drugs by releasing the drug slowly over an extended period of time Matrix tablets may be formulated by wet granulation or direct compression methods by dispersing solid particles within a porous matrix formed of hydrophilic and hydrophobic polymers. The use of different classes of polymers in controlling the release of drugs has become the most important aspect in the formulation of matrix tablets. The drug release in 
Indo Global Journal of Pharmaceutical Sciences, 2016; 6(1): 38-42

matrix drug delivery systems by both dissolution-controlled as

well as diffusion controlled mechanisms [1-3].

Advantages of Matrix Tablets [2,3]

-Easy to manufacture

-Versatile, effective and low cost

- Can be made to release high molecular weight compounds

-Unlike reservoir and osmotic systems, product based on

matrix design can be manufactured using conventional

processes and equipment.

Disadvantages of the matrix systems [2-4]

-The remaining matrix must be removed after the drug has been released.

-The drug release rates vary with the square root of time.

-Matrix tablet lack flexibility

\section{MECHANISM OF DRUG RELEASE FROM MATRIX SYSTEM [4-6]}

\section{1) Diffusion method}

In this method drug in the outside layer exposed to the bathing solution is dissolved first and then diffuses out of the matrix. This process continues with the interface between the bathing solution and the solid drug moving towards the interior. It follows that for this system to be diffusion controlled, the rate of dissolution of drug particles within the matrix must be much faster than the diffusion rate of dissolved drug leaving the matrix.

Derivation of the mathematical model to describe this system involves following assumption:

- A pseudo steady state is maintained during drug release

- The diameter of the drug particles is less than the average distance of the drug diffusion through the matrix

- The bathing solution provides sink condition at all the times.

The release behavior for the system can be mathematically described by following equation:

$$
\mathrm{Dm} / \mathrm{Dh}=\mathrm{Co} . \mathrm{dh}-\mathrm{Cs} / 2 .
$$

Where, $\mathrm{Dm}=$ change in amount of drug release per unit area.

Dh $=$ change in thickness of the zone of matrix than has been depleted of drug.

$\mathrm{Co}=$ total amount of drug

$\mathrm{Cs}=$ saturated concentration of drug within the matrix.
According to diffusion theory,

$$
\mathrm{Dm}=\mathrm{Dm} \cdot \mathrm{Cs} / \mathrm{h} \cdot \mathrm{dt} .
$$

Where, $\mathrm{Dm}=$ diffusion coefficient in the matrix $\mathrm{H}=$ thickness of the drug - depleted matrix

By combining equation (1) and equation (2) and integrating:

$$
\mathrm{M}=[\mathrm{Cs} . \mathrm{Dm}(2 \mathrm{C} 0-\mathrm{Cs}) \mathrm{t}] 1 / 2 \text {. }
$$

When the amount of drug is in excess of the saturation concentration then:

$$
\mathrm{M}=[2 \mathrm{Cs} . \mathrm{Dm} . \mathrm{C} 0 . \mathrm{t}] 1 / 2
$$

Equation (3) and eq. (4) relate the amount of drug release to the square-root of time. Therefore, if a system is predominantly diffusion controlled, then it is expected that a plot of the drug release vs. square root of time will result in a straight line.

\section{2) Bimodal release}

In certain system there is a bimodal release of the active ingredients. In this system there is diffusion. The extended release drug may become hydrated and begins to dissolve leading to release upon erosion. These systems are complex and difficult to mathematically model since the diffusion path length undergoes change due to polymer dissolution.

\section{Steps in bimodal release of matrix tablet}

- Water concentration gradient at polymer/water interface resulting in absorption of water into the matrix

- Due to absorption of water, the polymer swells

- Upon contact with water the drug dissolves and diffuses out of the matrix.

- With increasing water content, the diffusion coefficient of the drug increases substantially.

\section{3) Higuchi model}

The drug release from Higuchi model is much slower than zero order profile. When a matrix tablet is placed in the dissolution medium, the initial drug release occurs from the tablet superficial layer and consequently, the release rate is fast. As the time passes, the external layers of the tablet become depleted of the drug and water molecule must travel through long, tortuous channels to reach the drug remaining in the deeper layer of the tablet. Similarly, the drug solution that is formed within the tablet must diffuse through long capillaries to reach the external dissolution 


\section{Indo Global Journal of Pharmaceutical Sciences, 2016; 6(1): 38-42}

medium. The primary reason for continuously decreasing rate of the drug release is more than the matrix swells, the longer the diffusion path length required for the drug to come out.

In 1985, Peppas introduced a semi-empirical equation describing the drug release behavior from anomalous- release, hydrophilic matrix systems:

$$
\mathrm{Q}=\mathrm{k} . \mathrm{t} \mathrm{n}
$$

Where, $Q=$ Fraction of drug release in time $(t) t=$ Time $k=$ Rate constant (incorporates characteristics of polymer system and drug) $\mathrm{n}=$ Diffusional exponent

\section{CLASSIFICATION OF MATRIX TABLET [4, 6-12]}

\section{1) On the basis of retardant material}

\section{(a) Hydrophobic matrices}

The concept of using hydrophobic or inert material as matrix tablet was first introduced in 1959. In this method to obtain a sustained release from an oral dosage form, drug is mixed is mixed with a hydrophobic or inert polymer and then compressed to a tablet. Sustained released is obtained because the dissolving drug is diffused through a network of channels that exist between compacted polymer particles. This is the only system where the use of polymer is not essential to provide controlled drug release, although insoluble polymers have been used. As the name suggests the primary rate controlling component of hydrophobic matrix are water insoluble in nature such as waxes, fatty acids, glycerides and polymeric materials such as methyl cellulose, ethyl cellulose to modulate the release rate of drug.

\section{(b) Lipid matrices}

These matrices are prepared by lipid waxes and related materials. Drug release from such material occurs through both pore diffusion and erosion. Release characteristic are therefore more sensitive to digestive fluid composition than to totally insoluble polymer matrix.

\section{(c) Hydrophilic matrix tablets:}

Hydrophilic matrix systems are presently one of the most interesting drug delivery systems. They are most widely used to control the release rate of drugs because of their flexibility to obtain a desirable drug release profile, cost effectiveness, and broad regulatory acceptance. Hydrophilic matrix tablets may be defined as "Homogeneous dispersion of drug molecules within a skeleton of hydrophilic polymers, such as cellulose derivatives, sodium alginate, xanthan gum, polyethylene oxide, or carbopol among others, that swells upon contact with water". These systems are called swellable-controlled release systems. The release rate observed is possibly the zero-order release. Most commercial hydrophilic matrices are obtained by compression. Thus, the basic operations involved in the preparation of the matrices are the same as those used to prepare conventional tablets.

The polymers used in the preparation of hydrophilic matrices are divided into 3 groups:

A. Cellulose derivatives: Methylcellulose 400 and 4000cPs, hydroxyethylcellulose, hydroxypropylmethylcellulose (HPMC) 25, 100, 4000 and $15000 \mathrm{cPs}$ and sodium carboxymethylcellulose.

B. Non cellulose natural or semi synthetic polymers: Agar-Agar, carbo gum, alginates, molasses, polysaccharides of mannose and galactose, chitosan and modified starches.

C. Polymers of acrylic acid: Carbopol 934

\section{2) On the basis of porosity of matrix}

(a) Macro porous Systems: In such systems the diffusion of drug occurs through pores of matrix, which are of size range 0.1 to $1 \mu \mathrm{m}$. This pore size is larger than diffusing molecule size.

(b) Micro porous System: Diffusion in this type of system occurs essentially through pores. For micro porous systems, pore size ranges between $50-200 \mathrm{~A}^{\circ}$, which is slightly larger than diffusing molecule size.

(c) Polymers used in matrix tablet: Natural gums are biodegradable and nontoxic, which hydrate and swell on contact with aqueous media, and these have been used widely used now a day for preparation of matrix tablet.

There are number of polymers which may be used to formulate matrix tablets depending on the physicochemical properties of the drug substance to be incorporated into matrix system and type of drug release required. 
Indo Global Journal of Pharmaceutical Sciences, 2016; 6(1): 38-42

Table1(a) Various classes of polymers with examples[2,3,5,7-9, 11-17]

\begin{tabular}{|c|c|c|c|c|c|}
\hline Hydrogels & Soluble polymers & Biodegradable polymers & $\begin{array}{l}\text { Nonbiodegradable } \\
\text { polymers }\end{array}$ & $\begin{array}{l}\text { Mucoadhesive } \\
\text { polymers }\end{array}$ & Naturals gun \\
\hline $\begin{array}{l}\text { 1.Polyhydroxyethyl } \\
\text { methylacrylate(PHEMA) } \\
\text { 2.Crosslinked } \\
\text { polyvinylalcohol(PVA) } \\
\text { 3.Crosslinked } \\
\text { polyvinylpyrrodine(PVP) } \\
\text { 4.Polyoxyethylene(PEO) } \\
\text { 5.Polyacrylamide(PA) }\end{array}$ & $\begin{array}{lr}\text { 1.Polyethylene } & \text { glycol } \\
\text { (PEG) } & \text { 2.Polyvinyl } \\
\text { alcohol } & \text { (PVA) } \\
\text { 3.Polyvinyl pyrrolidone } \\
\text { (PVP) 4.Hydroxypropyl } \\
\text { methyl cellulose (HPMC) }\end{array}$ & $\begin{array}{l}\text { 1. Polylactic acid (PLA) } \\
\text { 2.Polyglycolic acid (PGA) } \\
\text { 3.Polycaprolactone (PCL) } \\
\text { 4.Polyanhydrides } \\
\text { 5.Polyorthoesters }\end{array}$ & $\begin{array}{l}\text { 1. Polyethylene vinyl } \\
\text { acetate (PVA) } \\
\text { 2. Polydimethyl } \\
\text { siloxane (PDS) } \\
\text { 3.Polyether urethane } \\
\text { (PEU) 4.Polyvinyl } \\
\text { chloride (PVC) } \\
\text { 5.Cellulose acetate } \\
\text { (CA) } \\
\text { 6.Ethyl cellulose } \\
\text { (EC) }\end{array}$ & $\begin{array}{l}\text { 1.Polycarbophil, } \\
\text { 2.Sodium } \\
\text { Carboxymethyl } \\
\text { cellulose } \\
\text { 3.Polyacrylic acid } \\
\text { 4. Tragacanth } \\
\text { 5. Methyl cellulo } \\
\text { 6. Pectin }\end{array}$ & $\begin{array}{l}\text { 1.Xanthan } \\
\text { gum } \\
\text { 2. Guar gum } \\
\text { 3.Karaya gum } \\
\text { Gum } \\
\text { Arabic 5.Locu } \\
\text { bean gum }\end{array}$ \\
\hline
\end{tabular}

Table 1(b) Various Polymers with their properties used in matrix tablet $[1,2,5,7,12,13,16-20]$

\begin{tabular}{|c|c|c|c|}
\hline Polymer & Molecular weight & Solubility & Ph/ melting point \\
\hline HPMC & $10000-1500000$ & $\begin{array}{l}\text { Soluble in boiling water and insoluble in ethanol and isopropyl } \\
\text { alcohol }\end{array}$ & $\begin{array}{l}5.5-8 \\
190-200^{\circ} \mathrm{C}\end{array}$ \\
\hline Xanthium gum & $2 \times 10^{6}$ & Practically insoluble in ethanol and ether and soluble in warm water & $\begin{array}{l}6-8 \\
270^{\circ} \mathrm{C}\end{array}$ \\
\hline Carbopol & $7 \times 10^{5}-4 \times 10^{9}$ & Soluble in water & $\begin{array}{l}2.5-3 \\
260^{\circ} \mathrm{C}\end{array}$ \\
\hline Hydrogels & & Insoluble in water & $\begin{array}{l}5.5-8.5 \\
50-400^{\circ} \mathrm{C}\end{array}$ \\
\hline Eudragit & 250000 & Soluble in water, acetone and alcohol & $58-59^{\circ} \mathrm{C}$ \\
\hline Guar gum & 220000 & $\begin{array}{l}\text { Insoluble in organic solvent and in cold and hot water } \\
\text { swells immediately }\end{array}$ & $5-7$ \\
\hline Tragacanth & 840000 & $\begin{array}{l}\text { It appears to be composed of two different constituents, one } \\
\text { soluble in water and the other swelling in water, but not dissolving. } \\
\text { Tragacanth is wholly insoluble in alcohol. }\end{array}$ & $5-6$ \\
\hline Starch & 9000 & $\begin{array}{l}\text { Soluble in } 1 \text { in } 10 \text { parts dichloromethane, } 1 \text { in } 2.5 \text { parts ethanol, } 1 \\
\text { in } 2 \text { parts methanol and } 1 \text { in } 2 \text { parts water. }\end{array}$ & - \\
\hline Ethyl cellulose & $200-4000$ & $\begin{array}{l}\text { Insoluble in water and soluble in organic solvent such as alcohol, } \\
\text { ether, ketone, ester, aromatic hydrocarbon and halo hydrocarbon etc. }\end{array}$ & $240-255^{\circ} \mathrm{C}$ \\
\hline $\begin{array}{l}\text { Sodium } \\
\text { carboxymethylcellulos }\end{array}$ & $90000-700000$ & Easily soluble in cold and hot water. & $592^{\circ} \mathrm{C}$ \\
\hline Agar & - & Soluble in boiling water and insoluble in ethanol & $4-10$ \\
\hline Acacia & $240000-580000$ & $\begin{array}{l}\text { Soluble in } 1 \text { in } 20 \text { parts glycerin, } 1 \text { in } 20 \text { propylene, } 1 \text { in } 2.7 \text { water } \\
\text { and insoluble in ether }\end{array}$ & $4.5-5$ \\
\hline Hydroxyethylcellulose & - & $\begin{array}{l}\text { Soluble in hot and cold water and insoluble in acetone, ether } \\
\text { and ethanol }\end{array}$ & $\begin{array}{l}5.5-8.5 \\
205^{\mathrm{O}} \mathrm{C}\end{array}$ \\
\hline Hydroxymethylcelluld & - & $\begin{array}{l}\text { Soluble in cold water and insoluble in hot water, acetone, ether } \\
\text { and ethanol. }\end{array}$ & $5.5-8$ \\
\hline Povidone & $2500-3000000$ & $\begin{array}{l}\text { Freely soluble in acids, chloroform, ethanol, ketones, methanol } \\
\text { and water. Insoluble in ether, hydrocarbon and mineral oil. }\end{array}$ & $100-260^{\circ} \mathrm{C}$ \\
\hline Hydroxypropylcellulo & $50000-3000000$ & Insoluble in water and most organic solvents. & $\begin{array}{l}5-8.5 \\
260-275^{\circ} \mathrm{C}\end{array}$ \\
\hline Pectin & $30000-100000$ & Soluble in water and insoluble in ethanol and other organic solvent. & $6-7.2$ \\
\hline Polyvinyl alcohol & $20000-200000$ & $\begin{array}{l}\text { Soluble in water, slightly soluble in ethanol and insoluble in } \\
\text { organic solvent. }\end{array}$ & $228^{\mathrm{O}} \mathrm{C}$ \\
\hline Karaya gum & $16 \times 10^{6}$ & $\begin{array}{l}10 \% \text { of native gum is soluble in cold water, } 30 \% \text { is soluble in hot } \\
\text { water. After deacetylation with ammonia } 90 \% \text { is dissolved in water. }\end{array}$ & $\begin{array}{l}4-4.7 \\
83.5^{\mathrm{O}} \mathrm{C}\end{array}$ \\
\hline Polyethylene glycol & $190-9000$ & All grades of PEG are soluble in water. & $\begin{array}{l}4-7.5 \\
37-63^{\mathrm{O}} \mathrm{C}\end{array}$ \\
\hline Polymethacrylates & 250000 & Soluble in water, acetone, alcohol and intestinal fluid ph 5.5 & $\begin{array}{l}5.5-8.5 \\
50-400^{\mathrm{O}} \mathrm{C}\end{array}$ \\
\hline
\end{tabular}


Indo Global Journal of Pharmaceutical Sciences, 2016; 6(1): 38-42

\begin{tabular}{|l|l|l|l|}
\hline Cellulose acetate & $38000-122000$ & $\begin{array}{l}\text { It is soluble in acetone }- \text { water blends of varying } \\
\text { ratios, dichloromethane }- \text { ethanol blend, dimethyl formamide } \\
\text { and dioxane. }\end{array}$ & $230-300^{\circ} \mathrm{C}$ \\
\hline Poloxamer & $2090-14600$ & $\begin{array}{l}\text { Freely soluble in ethanol, propylene glycol and water. Sparingly } \\
\text { soluble in propan }-2-\text { ol. }\end{array}$ & $\begin{array}{l}5-7.4 \\
16-57^{\mathrm{O}} \mathrm{C}\end{array}$ \\
\hline Polycarbophil & $700000-4$ billion & $\begin{array}{l}\text { Carbophil polymers can swells in water to around } 1000 \text { times } \\
\text { their original volumes when exposed to a ph } 4-6 .\end{array}$ & $2.5-3$ \\
\hline
\end{tabular}

\section{CONCLUSION}

The aim of this review article has been on the formulation of sustained-release matrix tablets, mechanism of drug release through matrix system and various polymers used to design such system. From above discussion it can be concluded that matrix tablets have the advantage of patient compliance, efficiency of dosage form, cost effectiveness and once - daily dose over conventional dosage forms. Hence, a sustainedrelease matrix tablet offers a vast advancement in the field of solid oral dosage form.

\section{ACKNOWLEDGMENT}

Authors feel highly thankful to Gyani Inder Singh Institute of Professional Studies for providing resources required for fulfillment of this article.

\section{REFERENCES}

1. Vyas SP, Khar RK. Controlled drug delivery: Concept and advances. Vallabh Prakashan, 2002;(1):156 - 18.

2. Y.M Chien; concept and system design. Novel drug delivery system. Marcel Dekker, New Delhi. 1992;50(2):1 - 3 .

3. Misra AN. Transdermal drug delivery. Controlled and novel drug delivery system. 48(2):109 - 14 .

4. Lachman L, Herbert A and Liberman. The theory and practice of industrial pharmacy, Varghese publishing house, Mumbai. 1990; 318 .

5. Shargel L, Yu Andrew B.C., Wu-Pong Susanna, Modified release drug products, Applied Biopharmaceutics and Pharmacokinetics, 5th Edition, McGraw Hill, 1999, 170-178.

6. Brahmankar HA, Jaiswal SB, Biopharmaceutics and Pharmacokinetics A Treatise, Vallabh Prakashan, 2009 Reprint Edition, 348-65

7. Winching Z, Lijun S, Hongzhu D et al. Hydration, erosion and release behavior of guar based hydrophilic matrix tablets containing total alkaloids of Sephora alopecuroides. Drug development and industrial pharmacy. 20 35(5):594- 02

8. Kumar Kiran S., Rao Rama T, Jayaveera K.N. Matrix Tablets as Controlled drug delivery systems, Indo American Journal of Pharmaceutical Research. 2011; (4), 343-09.

9. Borguist P, Korner A, Larsson A. A model for the drug release from a polymeric matrix tablets-effect of swelling and dissolution, Journal of Controlled Release, 2006, 113, 216-25.

10. Sayed I. Rahman A, Gamal MM, El- Badry M, Preparation and comparative evaluation of sustained release metoclopramide hydrochloride matrix tablets, Saudi Pharmaceutical Journal, 2009 ; 17: 283-88.

11. Lichtenberger LM, Wang ZM, Romero JJ et al. Study of natural gums. Nature medicine. 1995; 11:154-58.

12. Maderuelo C, Zarzuelo A, Lanao Jose M., Critical factors in the release of drugs from sustained release hydrophilic matrices, Journal of Controlled Release, 2011, 154, 2-19

13. Munday DC, Cox PJ., "Compressed xanthan and Karaya gum matrices: hydration, erosion and drug release mechanisms", Int J Pharm 2000, 203, 179-92

14. Syed A, Karen Y., Guar gum based sustained release diltiazem. Pharmaceutical research. 1998; 15:1196 - 1201.

15. Borguist $\mathrm{P}$, Korner A, Larsson A. A model for the drug release from a polymeric matrix tablets-effect of swelling and dissolution, J Controlled Release 2006; 113: 216-25.

16. Singh BN, Kim KH. Floating drug delivery systems. Indian Journal of Pharmaceutical sciences. 2006; 63:235-59.

17. Martini L., Close M., Gravell K., "Use of a hydrophobic matrix for the sustained release of a highly water soluble drug, Drug Delivery Indian Pharm 2000, 26(1):79- 83.

18. Sayed I. Abdel-Rahman, Gamal MM, El- Badry M, Preparation and comparative evaluation of sustained release metoclopramide hydrochloride matrix tablets, Saudi Pharmaceutical Journal ,2009; 17: 283-88.

19. Garg G, Singh D, Saraf S, et al. The pain management of aceclofenac. Sciencedirect.com. 2007.

20. Munday DC, Cox PJ. Compressed xanthan and karaya gum matrices: hydration, erosion and drug release mechanisms", Int Journal of Pharmaceutical Sciences. 2000, $203: 179-92$.

Indo Global Journal of Pharmaceutical Sciences( ISSN 22491023 ; CODEN- IGJPAI; NLM ID: 101610675) indexed and abstracted in EMBASE(Elsevier), SCIRUS(Elsevier),CABI, CAB Abstracts, Chemical Abstract Services(CAS), American Chemical Society(ACS), Index Copernicus, EBSCO, DOAJ, Google Scholar and many more. For further details, visit 